\title{
Microwave-Assisted Synthesis and Anticancer Activity of Triazolyl Thiazolidine Derivatives of Pyrene
}

\author{
Avula Srinivas, ${ }^{1, \star}$ Pulluri Karthik, ${ }^{1}$ Malladi Sunitha ${ }^{2}$ \\ and Koduri Vasumathi Reddy ${ }^{3}$ \\ ${ }^{1}$ Department of Chemistry, Vaagdevi Degree \& PG College \\ ${ }^{2}$ Jayamukhi Institute of Technological Sciences, Narsampet, Warangal, Telangana \\ ${ }^{3}$ Department of Zoology, Vaagdevi Degree \& PG College \\ Kishanpura, Warangal, Telangana, India 506001 \\ *Corresponding author: E-mail: avula.sathwikreddy@gmail.com
}

Received: 03-29-2019

\begin{abstract}
In a one pot procedure a series of $(R)-2-((2 S, 3 S)-3-((1-(4-c h l o r o p h e n y l)-1 H-1,2,3-$ triazol-4-yl)methoxy)-3,6-dihydro-2H-pyran-2-yl)-3-phenylthiazolidin-4-ones 9a-g and 2-((2R)-2-((2S,3S)-3-((1-(4-chlorophenyl)-1H-1,2,3-triazol4-yl)methoxy)-3,6-dihydro-2H-pyran-2-yl)-4-oxo-3-phenylthiazolidin-5-yl)acetic acids 10a-g was prepared by condensation of (2S,3S)-3-((1-(4-chlorophenyl)-1H-1,2,3-triazol-4-yl)methoxy)-3,6-dihydro-2H-pyran-2-carbaldehyde with mercapto acids and primary amines in the presence of $\mathrm{ZnCl}_{2}$ under both microwave irradiation and conventional heating conditions. Characterization of new compounds has been done by means of IR, NMR, MS and elemental analysis. The cytotoxicity was assessed against a panel of four different human tumor cell lines: A549 derived from human alveolar adenocarcinoma epithelial cells (ATCC No. CCL-185), Hela derived from human cervical cancer cells (ATCC No. CCL-2), MDA-MB-231 derived from human breast adenocarcinoma cells (ATCC No. HTB22) and HEK 293 (normal human embryonic kidney cell line) using the MTT assays. Among the tested compounds $\mathbf{9 e}$ and $\mathbf{1 0 e}$ showed the most potent activity against MCF-7 breast cancer cell line with $\mathrm{IC}_{50}$ values of 1.91 and $1.95 \mu \mathrm{M}$, whereas $9 \mathbf{b}, \mathbf{1 0 b}, \mathbf{9 g}$ and $10 \mathrm{~g}$ showed promising activity against MDA-MB-231 and Hela cell lines with $\mathrm{IC}_{50}$ values of 5.84, 5.74, 7.89 and 7.65 $\mu \mathrm{M}$, respectively.
\end{abstract}

Keywords: Glycosides; click reaction; cyclisation; thiazolidinones; anticancer activity

\section{Introduction}

Carbohydrates, besides being the most abundant class of bio-molecules, a vital source of energy and structural components, have an important role in biological processes, organic synthesis and chemical industries. ${ }^{1}$ In the chemical industry they act as readily available raw materials for large scale applications and have been used in the pharmaceutical, food, cosmetic and detergent industries. ${ }^{2}$ They have an important role in cell physiology in the form of glycoconjugates (glycolipids, glycoproteins and polysaccharides) and in many biological processes such as intercellular recognition, bacterial and viral infection, cancer metastasis, apoptosis and neuronal proliferation, etc. ${ }^{3}$

The introduction of a carbohydrate moiety into a system often imparts interesting properties, such as hydro- philicity, lowered toxicity and enhanced bioactivities. ${ }^{4} \mathrm{Or}-$ ganic chemists have linked carbohydrates to various biologically potent compounds to enhance their biological applications, such as steroids, aminoacids and other therapeutic agents. ${ }^{5}$ One of the methods used to link a carbohydrate moiety with a potential compound is via a triazole ring using the well known click-chemistry reactions. ${ }^{6}$ The versatility of the alkyne- azide cyclisation reaction and the introduction of a triazole ring makes this process an efficient method to obtain cyclized products with biological potential. ${ }^{7}$ The strategy of linking a carbohydrate moiety with another species via a triazole ring is gaining importance in organic synthesis, natural products chemistry and biochemistry. ${ }^{8}$ The stability, polar nature and possible hydrogen bonding ability of a triazole ring combined with the biocompatibility and presence of stereogenic centers of 
a carbohydrate moiety makes glucal-based triazole very interesting for organic synthetic chemists.

1,2,3-Triazoles are one of the most important classes of heterocyclic organic compounds, which are reported to be involved in a plethora of biological activities and to be present in diverse therapeutic areas. ${ }^{9}$ The 1,2,3-triazole motif is associated with diverse pharmacological activities such as antibacterial, antifungal, hypoglycemic, antihypertensive and analgesic properties. Polysubstituted five-membered aza heterocycles rank as the most potent glycosidase inhibitors. ${ }^{10}$ Further, this nucleus in combination with or in linking with various other classes of compounds such as amino acids, steroids, aromatic compounds, carbohydrates etc became prominent in having various pharmacological properties. ${ }^{11} 1,2,3$-Triazole modified carbohydrates have became easily available after the discovery of the $\mathrm{Cu}(\mathrm{I})$ catalyzed azide-alkynes 1,3-dipolar cycloaddition reaction ${ }^{12}$ and quickly became a prominent class of non-natural sugars. The chemistry and biology of triazole modified sugars is dominated by triazole glycosides. ${ }^{13}$ Therefore, the synthesis and investigation of biological activity of 1,2,3-triazole glycosides is an important objective, which also received a considerable attention by the medicinal chemists.

Thiazolidinone and its derivatives are known to possess significant pharmacological ${ }^{14}$ and biological activities, ${ }^{15}$ like sedative, ${ }^{16}$ anti inflammatory ${ }^{17}$ anti tubercular, ${ }^{18}$ anticancer, ${ }^{19}$ anti tumor, ${ }^{20}$ anti-HIV, ${ }^{21}$ anti bacteri$\mathrm{al}^{22}$ anti fungal, ${ }^{23}$ analgesic, hypotermic, ${ }^{24}$ anesthetic, ${ }^{25}$ nematicidal ${ }^{26}$ and CNS stimulant. ${ }^{27}$ Furthermore, thiazolidinones have been used for the treatment of cardiac diseases, ${ }^{28}$ diabetic complications like cataract nephropathy, neuropathy, ${ }^{29}$ and as selective anti platelet activating factor. $^{30}$

Microwave irradiation is an alternative heating technique based on the transformation of electromagnetic energy into heat. Often this method increases the rate of chemical reactions ${ }^{31}$ and results in higher yields. In recent years, multi component reactions (MCRs) ${ }^{32-36}$ have received interesting attention due to their simplicity, efficiency, atom economy, shortened reaction times, and the possibility for diversity oriented synthesis.

Following the successful introduction, inspired by the biological profile of triazoles, thiazolidinones, and in the continuation of our work on biologically active heterocycles $^{37-46}$ we have developed a series of novel triazolyl thiazolidine derivatives of pyrene, and evaluated their anticancer activity.

\section{Results and Discussion}

The key intermediate 8 required for the synthesis of the title compound was prepared according to the procedure outlined in the Scheme 1. Diacetyl-D-glucal (2) prepared from 3,4,6-tri-O-acetyl-D-glucal by treating with triethyl silane and boron trifluoride diethyl etherate, deacylation of 2 , with $\mathrm{NaOMe}$ in methanol at $0{ }^{\circ} \mathrm{C}$ for $1 \mathrm{~h}$ gave 3 (77\%), which on subsequent treatment with TBDMSCl in dichloromethane in the presence of $\mathrm{NEt}_{3}$ after $12 \mathrm{~h}$ afforded TBS ether $4(80 \%)$, on treatment with propargyl bromide in toluene in the presence of tetrabutylammonium hydrogensulphate produced diether 5 . After deprotection of TBS ether, the propargyl ether was converted into triazole $7(82 \%)$ by using 1,3-dipolar cycloaddition with para-chlorophenyl azide carried out at ambient temperature in the presence of $\mathrm{CuSO}_{4}$ and sodium ascorbate in a mixture of $1: 1 \mathrm{CH}_{2} \mathrm{Cl}_{2}-\mathrm{H}_{2} \mathrm{O}$. Oxidation of 7 with IBX in acetonitrile afforded compound 8 . Subsequently one-pot synthesis of triazole linked thiazolidenone glycosides was carried out by the condensation reaction between $\mathbf{8}$, primary aromatic amine and a thioglycolic acid in the presence of $\mathrm{ZnCl}_{2}$ under microwave irradiation/conventional heating (Scheme 2). In the classical method, the reactions were performed in dry toluene at reflux for a long time $(2-4 \mathrm{~h})$, often leading to degradation processes and consequent low yields of isolated products, whereas with the application of microwave assisted technology, the reactions were completed in only 5-10 minutes and the compounds were isolated by conventional work-up; products $\mathbf{9 a}-\mathbf{g}$ and 10a-g were obtained in satisfactory yields, often higher than those achieved by traditional methods. The structures of synthesized compounds were confirmed by IR, NMR, MS and elemental analysis and evaluated for their anticancer activity.

\section{In vitro Cytotoxicity}

Cytotoxicity of all the synthesized compounds was determined on the basis of measurement of in vitro growth inhibition of tumor cell lines in 96 well plates by cell-mediated reduction of tetrazolium salt to water-insoluble formation of crystals using doxorubicin as a standard. The cytotoxicity was assessed against a panel of four different human tumor cell lines: A549 derived from human alveolar adenocarcinoma epithelial cells (ATCC No. CCL-185), Hela derived from human cervical cancer cells (ATCC No. CCL-2), MDA-MB-231derived from human breast adenocarcinoma cells (ATCC No. HTB22) and HEK 293 (normal human embryonic kidney cell line) using the MTT assays. ${ }^{34}$ The $\mathrm{IC}_{50}$ values were calculated from the plotted absorbance data for the dose-response curves. $\mathrm{IC}_{50}$ values (in $\mu \mathrm{M}$ ) are indicated as means $\pm \mathrm{SD}$ of three independent experiments. From the data reported in Table 2, most of the prepared compounds (note: the enantiomeric purity of the final products was not established) possessed significant cytotoxicity effect on all the tested cell lines and potencies of some of the compounds were comparable to the standard doxorubicin, the most widely used drug for the treatment of tumors. Among the tested compounds $9 \mathbf{e}$ and 10e showed the most potent activity against MCF-7 cell 
line with $\mathrm{IC}_{50}$ values of 1.91 and $1.95 \mu \mathrm{M}$, respectively, whereas $9 \mathrm{~b}, 10 \mathrm{~b}, 9 \mathrm{~g}$ and $10 \mathrm{~g}$ showed promising activity against MDA-MB-231 and Hela cell lines with $\mathrm{IC}_{50}$ values of $5.84,5.74,7.89$ and $7.65 \mu \mathrm{M}$, respectively.

\section{Experimental}

Commercial grade reagents were used as supplied. Solvents except analytical reagent grade were dried and purified according to literature when necessary. Reaction progress and purity of the compounds were checked by thin-layer chromatography (TLC) on pre-coated silica gel F254 plates from Merck and compounds visualized either by exposure to UV light or dipping in $1 \%$ aqueous potassium permanganate solution. Silica gel chromatographic columns (60-120 mesh) were used for separations. Optical rotations were measured on an Perkin-Elmer 141 polarimeter by using a $2 \mathrm{~mL}$ cell with a path length of $1 \mathrm{dm}$ with $\mathrm{CHCl}_{3}$ or $\mathrm{CDCl}_{3}$ as the solvent. All melting points are uncorrected and were measured using Fisher-Johns apparatus. IR spectra were recorded as $\mathrm{KBr}$ disks on a PerkinElmer FT IR spectrometer. Microwave reactions were carried out in mini lab microwave catalytic reactor (ZZKD, WBFY-201). The ${ }^{1} \mathrm{H}$ NMR and ${ }^{13} \mathrm{C}$ NMR spectra were recorded on a Varian Gemini spectrometer $\left(300 \mathrm{MHz}\right.$ for ${ }^{1} \mathrm{H}$ and $75 \mathrm{MHz}$ for ${ }^{13} \mathrm{C}$ ). Chemical shifts are reported as $\delta$ (ppm) against TMS as the internal reference and coupling constants $(J)$ are reported in $\mathrm{Hz}$ units. Mass spectra were recorded on a VG micro mass $7070 \mathrm{H}$ spectrometer. Elemental analysis $(\mathrm{C}, \mathrm{H}, \mathrm{N})$ were determined by a PerkinElmer $240 \mathrm{CHN}$ elemental analyzer, and are within $\pm 0.4 \%$ of theoretical values.

((2R,3S)-3-Acetoxy-3,6-dihydro-2H-pyran-2-yl)methyl acetate (2). Tri- $O$-acetyl-D-glucal (1) $(3.0 \mathrm{~g}, 11.02 \mathrm{mmol})$ was dissolved in anhydrous dichloromethane $(5 \mathrm{~mL})$. The solution was cooled to $0{ }^{\circ} \mathrm{C}$, triethylsilane $(1.53 \mathrm{~g}, 13.22$ $\mathrm{mmol}$ ) was added and the mixture was stirred for five minutes. Next boron trifluoride diethyl etherate $(690 \mu \mathrm{L}$ of a $40 \%$ wt. solution in diethyl ether, $11.02 \mathrm{mmol}$ ) was added dropwise and the reaction mixture was stirred for $90 \mathrm{~min}$. The mixture was poured into a saturated solution of $\mathrm{NaH}-$ $\mathrm{CO}_{3}$. The organic layer was washed with water, dried over $\mathrm{Na}_{2} \mathrm{SO}_{4}$ and concentrated under reduced pressure. Column chromatography on silica gel (PE-EtOAc, 3:1) yielded the title compound $(2.24 \mathrm{~g}, 10.42 \mathrm{mmol}, 95 \%)$ as a colourless syrup. $[\boldsymbol{\alpha}]_{20}{ }_{20}:+115.5\left(c=1.00, \mathrm{CHCl}_{3}\right) .{ }^{1} \mathrm{HNMR}$ $\left(300 \mathrm{MHz}, \mathrm{CDCl}_{3}\right): \delta 5.87-5.84(\mathrm{~m}, 2 \mathrm{H},=\mathrm{CH}), 4.95(\mathrm{t}, 1 \mathrm{H}$, $\mathrm{OCH}), 4.03-3.99(\mathrm{~m}, 1 \mathrm{H}, \mathrm{CH}), 4.12-4.09\left(\mathrm{~m}, 4 \mathrm{H}, \mathrm{OCH}_{2}\right)$, $2.20\left(\mathrm{~s}, 6 \mathrm{H}, \mathrm{COCH}_{3}\right) ;{ }^{13} \mathrm{C} \mathrm{NMR}\left(75 \mathrm{MHz}, \mathrm{CDCl}_{3}\right): \mathrm{d} 170.2$, 127.2, 125.8, 73.6, 65.1, 64.0, 62.5, 21.1; MS: $m / z\left(\mathrm{M}^{+}+\mathrm{H}\right)$ 215. Anal. Calcd for $\mathrm{C}_{10} \mathrm{H}_{14} \mathrm{O}_{5}: \mathrm{C}, 56.07 ; \mathrm{H}, 6.59$. Found: $\mathrm{C}$, 55.82; $\mathrm{H}, 6.35$.

$(2 R, 3 S)-2-((t e r t-B u t y l d i m e t h y l s i l y l o x y) m e t h y l)-3,6-d i-$ hydro-2H-pyran-3-ol (4). Diacetate $2(17.22 \mathrm{mmol})$ was treated by a catalytic amount of sodium methoxide in methanol $(100 \mathrm{~mL})$ at room temperature. After evaporation of the solvent, the free hydroxyl unsaturated glycoside was obtained in quantitative yield and used without further purification. This diol was treated with 2.50 equiv of TBDMSCl (3.14 g, $21.14 \mathrm{mmol}), 2.6$ equiv of $\mathrm{NEt}_{3}(3.2 \mathrm{~mL}$, $22.4 \mathrm{mmol}$ ), and 0.05 equiv of imidazole $(30 \mathrm{mg}, 0.43$ $\mathrm{mmol})$ in $\mathrm{CH}_{2} \mathrm{Cl}_{2}(30 \mathrm{~mL})$ at room temperature for $\mathrm{ca} .24$ $\mathrm{h}$ (until TLC analysis showed no more starting material). After addition of $25 \mathrm{~mL}$ of water and extraction with $3 \times 30$ $\mathrm{mL}$ of $\mathrm{CH}_{2} \mathrm{Cl}_{2}$, the organic layer was dried. After evaporation of the solvent under reduced pressure, the residue was purified by column chromatography using petroleum ether/ethyl acetate as the eluent yielding the title compound (1.94 g, $10.42 \mathrm{mmol}, 85 \%$ ) as a colourless syrup. ${ }^{1} \mathrm{H}$

Table 1. Synthesis of compounds $9 \mathrm{a}-\mathrm{g}$ and $10 \mathrm{a}-\mathrm{g}$

\begin{tabular}{ccccccc}
\hline Compound & $\mathbf{R}$ & Mol. Formula & \multicolumn{2}{c}{ Reaction time } & \multicolumn{2}{c}{ Yield } \\
& & & $\mathbf{A}(\mathbf{h})$ & $\mathbf{B}(\mathbf{m i n})$ & $\mathbf{A}$ & $\mathbf{B}$ \\
\hline $\mathbf{9 a}$ & $\mathrm{C}_{6} \mathrm{H}_{5}$ & $\mathrm{C}_{23} \mathrm{H}_{21} \mathrm{ClN}_{4} \mathrm{O}_{3} \mathrm{~S}$ & 4.5 & 7 & 62 & 80 \\
$\mathbf{9 b}$ & $4-\mathrm{Cl}_{-} \mathrm{C}_{6} \mathrm{H}_{4}$ & $\mathrm{C}_{23} \mathrm{H}_{20} \mathrm{Cl}_{2} \mathrm{~N}_{4} \mathrm{O}_{3} \mathrm{~S}$ & 3.5 & 5 & 71 & 89 \\
$\mathbf{9 c}$ & $4-\mathrm{NO}_{2}-\mathrm{C}_{6} \mathrm{H}_{4}$ & $\mathrm{C}_{23} \mathrm{H}_{20} \mathrm{ClN}_{5} \mathrm{O}_{5} \mathrm{~S}$ & 4.0 & 6 & 69 & 82 \\
$\mathbf{9 d}$ & $2-\mathrm{CH}_{3}-\mathrm{C}_{6} \mathrm{H}_{4}$ & $\mathrm{C}_{24} \mathrm{H}_{23} \mathrm{ClN}_{4} \mathrm{O}_{3} \mathrm{~S}$ & 3.0 & 8 & 63 & 86 \\
$\mathbf{9 e}$ & $4-\mathrm{CH}_{3}-\mathrm{C}_{6} \mathrm{H}_{4}$ & $\mathrm{C}_{24} \mathrm{H}_{23} \mathrm{ClN}_{4} \mathrm{O}_{3} \mathrm{~S}$ & 3.5 & 7 & 68 & 88 \\
$\mathbf{9 f}$ & $3-\mathrm{OH}-\mathrm{C}_{6} \mathrm{H}_{4}$ & $\mathrm{C}_{23} \mathrm{H}_{21} \mathrm{ClN}_{4} \mathrm{O}_{4} \mathrm{~S}$ & 4.0 & 6 & 79 & 86 \\
$\mathbf{9 g}$ & $4-\mathrm{OH}-\mathrm{C}_{6} \mathrm{H}_{4}$ & $\mathrm{C}_{23} \mathrm{H}_{21} \mathrm{ClN}_{4} \mathrm{O}_{4} \mathrm{~S}$ & 3.0 & 3 & 80 & 91 \\
$\mathbf{1 0 a}$ & $\mathrm{C}_{6} \mathrm{H}_{5}$ & $\mathrm{C}_{25} \mathrm{H}_{23} \mathrm{ClN}_{4} \mathrm{O}_{5} \mathrm{~S}$ & 4.5 & 8 & 63 & 79 \\
$\mathbf{1 0 b}$ & $4-\mathrm{Cl}-\mathrm{C}_{6} \mathrm{H}_{4}$ & $\mathrm{C}_{25} \mathrm{H}_{22} \mathrm{Cl}_{2} \mathrm{~N}_{4} \mathrm{O}_{5} \mathrm{~S}$ & 3.5 & 5 & 65 & 82 \\
$\mathbf{1 0 c}$ & $4-\mathrm{NO}_{2}-\mathrm{C}_{6} \mathrm{H}_{4}$ & $\mathrm{C}_{25} \mathrm{H}_{22} \mathrm{ClN}_{5} \mathrm{O}_{7} \mathrm{~S}$ & 4.0 & 7 & 61 & 79 \\
$\mathbf{1 0 d}$ & $2-\mathrm{CH}_{3}-\mathrm{C}_{6} \mathrm{H}_{4}$ & $\mathrm{C}_{26} \mathrm{H}_{25} \mathrm{ClN}_{4} \mathrm{O}_{5} \mathrm{~S}$ & 3.5 & 5 & 70 & 81 \\
$\mathbf{1 0}$ & $4-\mathrm{CH}_{3}-\mathrm{C}_{6} \mathrm{H}_{4}$ & $\mathrm{C}_{26} \mathrm{H}_{25} \mathrm{ClN}_{4} \mathrm{O}_{5} \mathrm{~S}$ & 3.0 & 5 & 67 & 82 \\
$\mathbf{1 0 f}$ & $3-\mathrm{OH}-\mathrm{C}_{6} \mathrm{H}_{4}$ & $\mathrm{C}_{25} \mathrm{H}_{23} \mathrm{ClN}_{4} \mathrm{O}_{6} \mathrm{~S}$ & 4.0 & 8 & 77 & 87 \\
$\mathbf{1 0 g}$ & $4-\mathrm{OH}-\mathrm{C}_{6} \mathrm{H}_{4}$ & $\mathrm{C}_{25} \mathrm{H}_{25} \mathrm{ClN}_{4} \mathrm{O}_{6} \mathrm{~S}$ & 2.5 & 4 & 79 & 90 \\
\hline
\end{tabular}

A: Conventional heating. B: microwave irradiation

Srinivas et al.: Microwave-Assisted Synthesis and Anticancer Activity ... 
<smiles>CC(=O)OC[C@H]1OC=C[C@H](OC(C)=O)[C@H]1OC(C)=O</smiles>

a<smiles>CC(=O)OC[C@H]1OCC=C[C@H]1OC(=O)O</smiles>

b<smiles>OC[C@H]1OCC=C[C@H]1O</smiles>

C

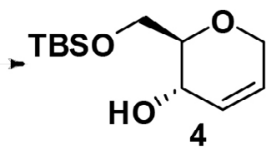<smiles>C1CCCCCC1</smiles><smiles>C#CCO[C@H]1C=CCO[C@@H]1CO[Sb]</smiles><smiles>C#CCO[C@H]1C=CCO[C@@H]1CO</smiles>

f<smiles>[3H]C[C@H]1OCC=C[C@@H]1OCc1cn(-c2ccc(Cl)cc2)nn1</smiles><smiles>[194IH]</smiles><smiles>O=CC1OCC=CC1OCc1cn(-c2ccc(Cl)cc2)nn1</smiles>

Scheme 1<smiles>O=CC1OCC=C[C@@H]1OCc1cn(-c2ccc(Cl)cc2)nn1</smiles>

Scheme 2

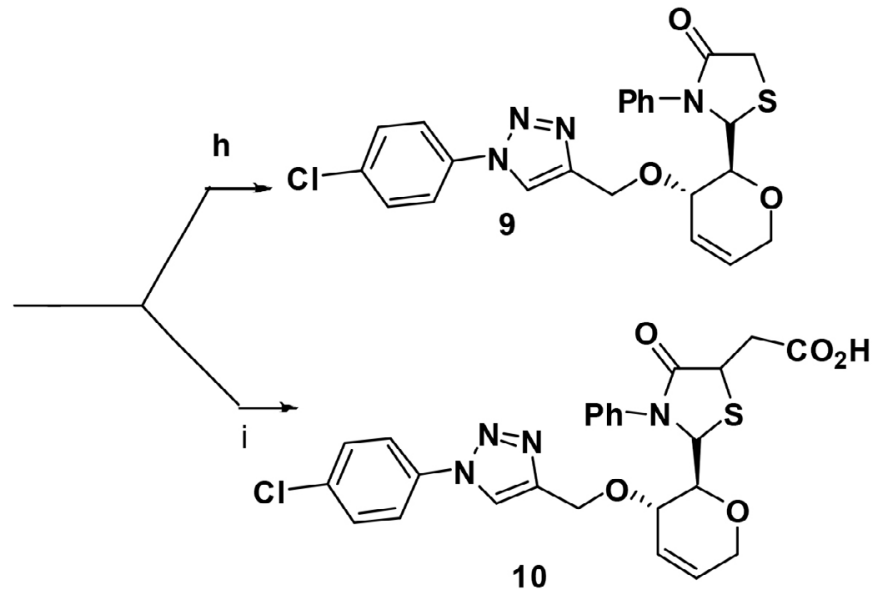

10

Reagents and conditions: (a) $\mathrm{BF}_{3}, \mathrm{Et}_{2} \mathrm{O}, \mathrm{Et}_{3} \mathrm{SiH}, \mathrm{CH}_{2} \mathrm{Cl}_{2}$. (b) $\mathrm{MeOH}, \mathrm{NaOMe}$. (c) TBDMSCl, $\mathrm{Et}_{3} \mathrm{~N}, \mathrm{CH}_{2} \mathrm{Cl}_{2}$. (d) Propargyl bromide, $\mathrm{NaH}, n-\mathrm{Bu}_{4} \mathrm{~N}$ $\mathrm{HSO}_{4}, 35 \% \mathrm{NaOH}$, toluene. (e) TBAF, THF. (f) $\mathrm{PhN}_{3}, \mathrm{CuSO}_{4}$, sodium ascorbate, $\mathrm{CH}_{2} \mathrm{Cl}_{2}, \mathrm{H}_{2} \mathrm{O}$ (1:1). (g) IBX, $\mathrm{CH}_{3} \mathrm{CN}$. (h) $\mathrm{PhNH}$, AcOH, SHCH${ }_{2} \mathrm{COOH}, \mathrm{ZnCl}_{2}, \mathrm{C}_{6} \mathrm{H}_{6}$. (i) $\mathrm{SHCHCOOHCH} \mathrm{H}_{2} \mathrm{COOH}, \mathrm{ZnCl}_{2}, \mathrm{C}_{6} \mathrm{H}_{6}$.

Table 2. $\mathrm{IC}_{50}$ values of tested compounds $9 \mathrm{a}-\mathrm{g}$ and $10 \mathrm{a}-\mathrm{g}$ against four human cell lines and normal cell line (HEK 293)

\begin{tabular}{|c|c|c|c|c|c|}
\hline \multirow[t]{2}{*}{ Compound } & \multicolumn{4}{|c|}{ IC $_{50}$ Values in $\mu \mathrm{M}$} & \multirow[t]{2}{*}{ HEK293 } \\
\hline & A549 & Hela & MDA-MB-231 & MCF-7 & \\
\hline $9 a$ & 4.89 & 2.98 & 13.34 & 5.31 & $>100$ \\
\hline $9 b$ & $>100$ & $>100$ & $>5.84$ & $>100$ & $>100$ \\
\hline $9 c$ & 5.44 & $>100$ & $>100$ & 8.95 & $>100$ \\
\hline 9d & $>100$ & $>100$ & $>100$ & $>100$ & $>100$ \\
\hline $9 e$ & 5.75 & $>100$ & $>100$ & 51.71 & $>100$ \\
\hline $9 f$ & $>100$ & 7.89 & $>100$ & $>100$ & $>100$ \\
\hline $9 g$ & $>100$ & $>100$ & 13.39 & 1.91 & $>100$ \\
\hline $10 \mathbf{a}$ & 4.67 & 3.03 & 13.56 & 5.62 & $>100$ \\
\hline $10 \mathrm{~b}$ & $>100$ & $>100$ & $>5.74$ & $>100$ & $>100$ \\
\hline $10 \mathrm{c}$ & 5.56 & $>100$ & $>100$ & 8.65 & $>100$ \\
\hline 10d & $>100$ & $>100$ & $>100$ & $>100$ & $>100$ \\
\hline $10 \mathrm{e}$ & 5.89 & $>100$ & $>100$ & 52.09 & $>100$ \\
\hline $10 f$ & $>100$ & 7.92 & $>100$ & $>100$ & $>100$ \\
\hline $10 \mathrm{~g}$ & $>100$ & $>100$ & 13.56 & 1.95 & $>100$ \\
\hline Doxorubicin & 0.459 & 0.509 & 0.91 & 1.07 & $>100$ \\
\hline
\end{tabular}

Srinivas et al.: Microwave-Assisted Synthesis and Anticancer Activity ... 
NMR $\left(300 \mathrm{MHz}, \mathrm{CDCl}_{3}\right): \delta 6.0-5.82(\mathrm{~m}, 2 \mathrm{H},=\mathrm{CH}), 5.42$ $(\mathrm{d}, J=6.5 \mathrm{~Hz}, 1 \mathrm{H}, \mathrm{CH}), 4.50$ (brs, $1 \mathrm{H}, \mathrm{OH}), 4.20-4.12(\mathrm{~m}$, $1 \mathrm{H}, \mathrm{CH}), 3.91-3.80\left(\mathrm{~m}, 4 \mathrm{H}, \mathrm{CH}_{2}\right), 0.98(\mathrm{~s}, 9 \mathrm{H}, t-\mathrm{Bu}), 0.24$ $\left(\mathrm{s}, 6 \mathrm{H}, \mathrm{CH}_{3}\right) ;{ }^{13} \mathrm{C}$ NMR $\left(75 \mathrm{MHz}, \mathrm{CDCl}_{3}\right): \mathrm{d} 127.5,125.6$, 84.6, 81.5, 73.6, 62.7, 25.6, 18.1; MS: $\mathrm{m} / z\left(\mathrm{M}^{+}+\mathrm{Na}\right) 267$. Anal. Calcd for $\mathrm{C}_{12} \mathrm{H}_{24} \mathrm{O}_{3} \mathrm{Si}$ : C, 58.97; H, 9.90. Found: C, 58.62; H, 9.75.

tert-Butyldimethyl $(((2 R, 3 S)$-3-(prop-2-ynyloxy)-3,6-dihydro-2H-pyran-2-yl)methoxy)silane (5). To a solution of alcohol 4 (400 mg, $1.63 \mathrm{mmol}, 1.0$ equiv) in toluene (1.6 $\mathrm{mL}$ ) was added a $35 \%$ aqueous solution of $\mathrm{NaOH}(1.6$ $\mathrm{mL}$ ),propargyl bromide ( $80 \%$ solution in toluene, $363 \mu \mathrm{L}$, $2.4 \mathrm{mmol}, 1.5$ equiv), and $n-\mathrm{Bu}_{4} \mathrm{NHSO}_{4}(280 \mathrm{mg}, 0.82$ mmol, 0.5 equiv). After $6 \mathrm{~h}$ of vigorous stirring at rt, Et${ }_{2} \mathrm{NH}(1.6 \mathrm{~mL})$ was added. The reaction mixture was stirred for $1 \mathrm{~h}$, poured into ice water, cautiously neutralized by addition of a $3 \mathrm{M}$ solution of hydrochloric acid, and extracted with EtOAc. The combined organic extracts were washed with brine, dried over $\mathrm{MgSO}_{4}$, filtered, and concentrated under reduced pressure. The crude material was purified by flash chromatography on silica gel (hexaneEtOAc 85:15) to afford propargyl ether as a colorless oil $(0.345 \mathrm{~g}, 75 \%) .{ }^{1} \mathrm{H}$ NMR $\left(300 \mathrm{MHz}, \mathrm{CDCl}_{3}\right): \delta 6.03-5.80$ $(\mathrm{m}, 2 \mathrm{H},=\mathrm{CH}), 4.69(\mathrm{t}, J=3.9 \mathrm{~Hz}, 1 \mathrm{H}, \mathrm{CH}), 3.68(\mathrm{dd}, J=8.9$ $\mathrm{Hz}, 4.1 \mathrm{~Hz}, 1 \mathrm{H}, \mathrm{OCH}), 3.99-3.89\left(\mathrm{~m}, 6 \mathrm{H}, \mathrm{CH}_{2}\right), 3.20(\mathrm{~s}$, $1 \mathrm{H}, \mathrm{CH}), 0.96(\mathrm{~s}, 9 \mathrm{H}, t-\mathrm{Bu}), 0.23\left(\mathrm{~s}, 6 \mathrm{H}, \mathrm{CH}_{3}\right) ;{ }^{13} \mathrm{C} \mathrm{NMR}$ $\left(75 \mathrm{MHz}, \mathrm{CDCl}_{3}\right): \mathrm{d} 127.2,124.9,78.0,76.2,74.2,64.2$, 63.2, 58.5, 25.3, 18.5; MS: $\mathrm{m} / z\left(\mathrm{M}^{+}+\mathrm{H}\right)$ 283. Anal. Calcd for $\mathrm{C}_{15} \mathrm{H}_{26} \mathrm{O}_{3} \mathrm{Si}: \mathrm{C}, 63.78 ; \mathrm{H}, 9.28$. Found: $\mathrm{C}, 63.62 ; \mathrm{H}, 8.95$.

((2R,3S)-3-(Prop-2-ynyloxy)-3,6-dihydro-2H-pyran-2yl)methanol (6). To a stirred solution of $5(0.325 \mathrm{~g})$ in tetrahydrofuran a catalytic amount of TBAF was added and stirred the reaction mixture at room temperature for 15 $\mathrm{min}$, extracted the product with ethyl acetate $(20 \mathrm{~mL})$. The combined organic extracts were washed with brine, dried over $\mathrm{MgSO}_{4}$, filtered, and concentrated under reduced pressure. The crude material was purified by flash chromatography on silica gel (60-120 mesh, hexane-EtOAc 70:30) to afford the title alcohol as yellow oil $(0.285 \mathrm{~g}, 85 \%) .{ }^{1} \mathrm{H}$ NMR $\left(300 \mathrm{MHz}, \mathrm{CDCl}_{3}\right): \delta 5.95-5.75(\mathrm{~m}, 2 \mathrm{H},=\mathrm{CH}), 4.65$ $(\mathrm{d}, J=3.9 \mathrm{~Hz}, 1 \mathrm{H}, \mathrm{CH}), 4.52$ (brs, $1 \mathrm{H}, \mathrm{OH}), 4.09-4.11(\mathrm{~m}$, $\left.4 \mathrm{H}, \mathrm{OCH}_{2}\right), 3.64(\mathrm{dd}, J=4.1 \mathrm{~Hz}, 8.9 \mathrm{~Hz}, 1 \mathrm{H}, \mathrm{OCH}), 3.76$ $\left(\mathrm{d}, J=6.8 \mathrm{~Hz}, 2 \mathrm{H}, \mathrm{OCH}_{2}\right), 3.28(\mathrm{~s}, 1 \mathrm{H}, \mathrm{CH}) ;{ }^{13} \mathrm{C}$ NMR $(75$ $\left.\mathrm{MHz}, \mathrm{CDCl}_{3}\right)$ : d 127.2, 125.6, 78.3, 76.1, 74.1, 64.2, 61.4, 58.0; MS: $m / z\left(\mathrm{M}^{+}+\mathrm{H}\right)$ 169. Anal. Calcd for $\mathrm{C}_{9} \mathrm{H}_{12} \mathrm{O}_{3}$ : C, 64.27; H, 7.10. Found: C, 64.02; H, 6.95.

((2R,3S)-3-((1-(4-Chlorophenyl)-1H-1,2,3-triazol-4-yl) methoxy)-3,6-dihydro-2H-pyran-2-yl)methanol (7). To a solution containing alkyne $6(0.250 \mathrm{~g}, 0.778 \mathrm{mmol}), p a-$ ra-chlorophenyl azide $(0.130 \mathrm{~g}, 0.849 \mathrm{mmol})$ in dichloromethane $(10 \mathrm{~mL})$ and water $(10 \mathrm{~mL})$ were added $\mathrm{Cu}$ $\mathrm{SO}_{4} \cdot 5 \mathrm{H}_{2} \mathrm{O}(0.110 \mathrm{~g})$ and sodium ascorbate $(0.114 \mathrm{~g})$. The resulting suspension was stirred at room temperature for 6 h. After this time, the mixture was diluted with $5 \mathrm{~mL}$ dichloromethane and $5 \mathrm{~mL}$ water.The organic phase was separated, dried with sodium sulphate and concentrated at reduced pressure. The crude product was purified by column chromatography on silica gel (60-120 mesh, hexaneEtOAc 65:35) to afford $7(0.290 \mathrm{~g}, 75 \%)$ as a white powder. M.p. $149-1510{ }^{\circ} \mathrm{C} .{ }^{1} \mathrm{H}$ NMR $\left(300 \mathrm{MHz}, \mathrm{CDCl}_{3}\right.$ ): $\delta 8.05$ (s, $1 \mathrm{H}, \mathrm{Ar}-\mathrm{H}), 7.56(\mathrm{~d}, J=9.2 \mathrm{~Hz}, 2 \mathrm{H}, \mathrm{Ar}-\mathrm{H}), 7.45$ (d, $J=8.9$ $\mathrm{Hz}, 2 \mathrm{H}, \mathrm{Ar}-\mathrm{H}), 5.85-5.79(\mathrm{~m}, 2 \mathrm{H},=\mathrm{CH}), 4.59(\mathrm{~s}, 2 \mathrm{H}$, $\left.\mathrm{OCH}_{2}\right), 4.50$ (brs, $\left.1 \mathrm{H}, \mathrm{OH}\right), 3.88-3.99\left(\mathrm{~m}, 4 \mathrm{H}, \mathrm{OCH}_{2}\right)$, 3.8-3.75 (m, 2H, OCH); ${ }^{13} \mathrm{C}$ NMR $\left(75 \mathrm{MHz}, \mathrm{CDCl}_{3}\right)$ : d $140.9,134.5,134.1,128.4,127.5,125.4,122.1,121.5,78.6$, 68.5, 65.7, 64.2, 62.4; MS: $m / z\left(\mathrm{M}^{+}+\mathrm{H}\right)$ 322. Anal. Calcd for $\mathrm{C}_{15} \mathrm{H}_{16} \mathrm{ClN}_{3} \mathrm{O}_{3}: \mathrm{C}, 55.90 ; \mathrm{H}, 5.01 ; \mathrm{N}, 13.06$. Found: $\mathrm{C}$, $55.65 ; \mathrm{H}, 4.95 ; \mathrm{N}, 12.86$.

(R)-2-((2S,3S)-3-((1-(4-Chlorophenyl)-1H-1,2,3-triazol4-yl)methoxy)-3,6-dihydro-2H-pyran-2-yl)-3-phenylthiazolidin-4-ones 8a-g. To a solution of alcohol $7(0.120 \mathrm{~g}$, $0.465 \mathrm{mmol})$ in $\mathrm{CH}_{2} \mathrm{Cl}_{2}(5 \mathrm{~mL})$, a catalytic amount of IBX was added at $0{ }^{\circ} \mathrm{C}$ and stirred at room temperature for $30 \mathrm{~min}$. The reaction mixture was filtered and washed with $\mathrm{CH}_{2} \mathrm{Cl}_{2}(2 \times 10 \mathrm{~mL})$. It was dried $\left(\mathrm{Na}_{2} \mathrm{SO}_{4}\right)$ and evaporated to give aldehyde $7(0.110 \mathrm{~g})$ in quantitative yield as a yellow liquid, which was used as such for the next reaction.

To a stirred mixture of $8(0.110 \mathrm{~g}, 0.373 \mathrm{mmol})$, aromatic amine $(0.373 \mathrm{mmol})$ and anhydrous thioglycolic acid $(0.140 \mathrm{~g}, 0.211 \mathrm{mmol})$ in dry toluene $(5 \mathrm{~mL}), \mathrm{ZnCl}_{2}$ $(0.100 \mathrm{~g}, 0.751 \mathrm{mmol})$ was added after $2 \mathrm{~min}$ and irradiated in microwave bath reactor at $280 \mathrm{~W}$ for 4-7 minutes at $110^{\circ} \mathrm{C}$. After cooling, the filtrate was concentrated to dryness under reduced pressure and the residue was taken up in ethyl acetate. The ethyl acetate layer was washed with $5 \%$ sodium bicarbonate solution and finally with brine. The organic layer was dried over $\mathrm{Na}_{2} \mathrm{SO}_{4}$ and evaporated to dryness at reduced pressure. The crude product thus obtained was purified by column chromatography on silica gel (60-120 mesh) with hexane-ethyl acetate as the eluent. Under conventional method the reaction mixture in toluene $(10 \mathrm{~mL})$ was refluxed at $110{ }^{\circ} \mathrm{C}$ for the appropriate time (Table 1).

(R)-2-((2S,3S)-3-((1-(4-Chlorophenyl)-1H-1,2,3-triazol-4-yl)methoxy)-3,6-dihydro-2H-pyran-2-yl)-3phenylthiazolidin-4-one (9a). M.p. $157-159^{\circ} \mathrm{C}$, IR (KBr) $v 3100,3010,1750,1620,1602,1440,1350,1340,1210,735$ $\mathrm{cm}^{-1} .{ }^{1} \mathrm{H}$ NMR $\left(300 \mathrm{MHz}, \mathrm{CDCl}_{3}\right): \delta 8.04(\mathrm{~s}, 1 \mathrm{H}, \mathrm{Ar}-\mathrm{H})$, $7.50(\mathrm{~d}, J=9.2 \mathrm{~Hz}, 2 \mathrm{H}, \operatorname{Ar}-\mathrm{H}), 7.40(\mathrm{~d}, J=8.9 \mathrm{~Hz}, 2 \mathrm{H}$, Ar-H), 7.10-6.20 (m, 5H, Ar-H), 5.80-5.71 (m, 2H, =CH), $4.90(\mathrm{~d}, J=5.2 \mathrm{~Hz}, 1 \mathrm{H}, \mathrm{CHS}), 4.52\left(\mathrm{~s}, 2 \mathrm{H}, \mathrm{OCH}_{2}\right), 4.09$ $3.94(\mathrm{~m}, 2 \times \mathrm{CH}), 3.79\left(\mathrm{~d}, J=6.6 \mathrm{~Hz}, 2 \mathrm{H}, \mathrm{OCH}_{2}\right), 3.72(\mathrm{~s}$, $\left.2 \mathrm{H}, \mathrm{CH}_{2}\right) .{ }^{13} \mathrm{C}$ NMR $\left(75 \mathrm{MHz}, \mathrm{CDCl}_{3}\right): \mathrm{d} 170.4,144.1$, $141.8,134.1,128.2,125.6,122.4,119.4,85.6,72.6,66.4$, 64.0, 51.4, 33.9: MS: $m / z\left(\mathrm{M}^{+}+\mathrm{H}\right)$ 469. Anal. Calcd for $\mathrm{C}_{23} \mathrm{H}_{21} \mathrm{ClN}_{4} \mathrm{O}_{3}$ S: C, 58.91; H, 4.51; N,11.95. Found: C, $58.68 ; \mathrm{H}, 4.35 ; \mathrm{N}, 11.66$. 
(R)-3-(4-Chlorophenyl)-2-((2S,3S)-3-((1-(4-chlorophenyl)-1H-1,2,3-triazol-4-yl)methoxy)-3,6-dihydro2H-pyran-2-yl)thiazolidin-4-one (9b). M.p. $226-228^{\circ} \mathrm{C}$. IR $(\mathrm{KBr}) \vee 3190,3018,1756,1616,1609,1430,1340,1320$, $1208,731 \mathrm{~cm}^{-1} .{ }^{1} \mathrm{H}$ NMR $\left(300 \mathrm{MHz}, \mathrm{CDCl}_{3}\right)$ : d $8.05(\mathrm{~s}, 1 \mathrm{H}$, Ar-H), $7.54(\mathrm{~d}, J=9.4 \mathrm{~Hz}, 4 \mathrm{H}, \mathrm{Ar}-\mathrm{H}), 7.42(\mathrm{~d}, J=8.6 \mathrm{~Hz}$, $4 \mathrm{H}, \mathrm{Ar}-\mathrm{H}), 5.84-5.75(\mathrm{~m}, 2 \mathrm{H},=\mathrm{CH}), 4.94(\mathrm{~d}, J=5.2 \mathrm{~Hz}$, CH-S), $4.50\left(\mathrm{~s}, 2 \mathrm{H}, \mathrm{OCH}_{2}\right), 4.06-3.96(\mathrm{~m}, 2 \mathrm{H}, 2 \times \mathrm{CH})$, $3.80\left(\mathrm{t}, 2 \mathrm{H}, \mathrm{OCH}_{2}\right), 3.72\left(\mathrm{~s}, 2 \mathrm{H}, \mathrm{CH}_{2}\right) ;{ }^{13} \mathrm{C} \mathrm{NMR}(75 \mathrm{MHz}$, $\left.\mathrm{CDCl}_{3}\right): \mathrm{d} 170.5,144.2,139.2,134.2,129.2,125.5,122.2$, 119.4, 85.4, 72.8, 65.4, 63.4, 51.2, 34.1. MS: $m / z\left(\mathrm{M}^{+}+\mathrm{Na}\right)$ 525. Anal. Calcd for $\mathrm{C}_{23} \mathrm{H}_{20} \mathrm{Cl}_{2} \mathrm{~N}_{4} \mathrm{O}_{3} \mathrm{~S}: \mathrm{C}, 54.88 ; \mathrm{H}, 4.00 ; \mathrm{N}$, 11.13. Found: C, $54.58 ; \mathrm{H}, 3.75 ; \mathrm{N}, 10.86$.

(R)-2-((2S,3S)-3-((1-(4-Chlorophenyl)-1H-1,2,3-triazol-4-yl)methoxy)-3,6-dihydro-2H-pyran-2-yl)-3-(4nitrophenyl)thiazolidin-4-one (9c). M.p. $211-213^{\circ} \mathrm{C}$. IR $(\mathrm{KBr})$ v 3112, 3020, 1746, 1626, 1619, 1560, 1435, 1344, $1324,1218,739 \mathrm{~cm}^{-1} .{ }^{1} \mathrm{H}$ NMR $\left(300 \mathrm{MHz}, \mathrm{CDCl}_{3}\right): \delta 8.26$ (d, $J=8.7 \mathrm{~Hz}, 2 \mathrm{H}), 8.03(\mathrm{~s}, 1 \mathrm{H}, \mathrm{Ar}-\mathrm{H}), 7.61(\mathrm{~d}, J=9.4 \mathrm{~Hz}$, $4 \mathrm{H}, \mathrm{Ar}-\mathrm{H}), 7.46$ (d, $J=8.5 \mathrm{~Hz}, 4 \mathrm{H}, \mathrm{Ar}-\mathrm{H}), 6.84(\mathrm{~d}, J=9.8$ $\mathrm{Hz}, 2 \mathrm{H}, \mathrm{Ar}-\mathrm{H}), 5.86-5.79(\mathrm{~m}, 2 \mathrm{H},=\mathrm{CH}), 4.96(\mathrm{~d}, J=5.2$ $\mathrm{Hz}, \mathrm{CH}-\mathrm{S}), 4.55$ (s, $\left.2 \mathrm{H}, \mathrm{OCH}_{2}\right), 4.05-3.95(\mathrm{~m}, 2 \mathrm{H}, 2 \times \mathrm{CH})$, $3.85\left(\mathrm{~d}, J=6.9 \mathrm{~Hz}, 2 \mathrm{H}, \mathrm{OCH}_{2}\right), 3.82\left(\mathrm{~s}, 2 \mathrm{H}, \mathrm{CH}_{2}\right) .{ }^{13} \mathrm{C}$ $\operatorname{NMR}\left(75 \mathrm{MHz}, \mathrm{CDCl}_{3}\right)$ : $\mathrm{d} 171.5,144.0,141.8,134.2,128.5$, 125.4, 119.5, 85.4, 72.4, 65.9, 63.6, 51.5, 34.6: MS: $\mathrm{m} / \mathrm{z}$ $\left(\mathrm{M}^{+}+\mathrm{H}\right)$ 514. Anal. Calcd for $\mathrm{C}_{23} \mathrm{H}_{20} \mathrm{ClN}_{5} \mathrm{O}_{5} \mathrm{~S}: \mathrm{C}, 53.75 ; \mathrm{H}$, 3.92; N, 13.63. Found: C, 53.58; H, 3.75; N, 13.39 .

(R)-2-((2S,3S)-3-((1-(4-Chlorophenyl)-1H-1,2,3-triazol-4-yl)methoxy)-3,6-dihydro-2H-pyran-2-yl)-3-ortho-tolylthiazolidin-4-one (9d). M. p. $191-193{ }^{\circ} \mathrm{C}$. (IR) $\mathrm{KBr} \vee 3116,3024,1741,1622,1615,1450,1439,1348$, $1321,1218,749 \mathrm{~cm}^{-1} .{ }^{1} \mathrm{H}$ NMR $\left(300 \mathrm{MHz}, \mathrm{CDCl}_{3}\right): \delta 8.08$ (s, 1H, Ar-H), $7.56(\mathrm{~d}, J=9.2 \mathrm{~Hz}, 2 \mathrm{H}, \mathrm{Ar}-\mathrm{H}), 7.49$ (d, $J=$ $8.7 \mathrm{~Hz}, 2 \mathrm{H}, \mathrm{Ar}-\mathrm{H}), 7.45-7.39$ (m, 4H, Ar-H), $5.76(\mathrm{~m}, 2 \mathrm{H}$, $=\mathrm{CH}), 4.93(\mathrm{~d}, J=5.2 \mathrm{~Hz}, 1 \mathrm{H}, \mathrm{CHS}), 4.60\left(\mathrm{~s}, 2 \mathrm{H}, \mathrm{OCH}_{2}\right)$, 4.05-3.96 (m, $2 \mathrm{H}, \mathrm{CH}), 3.90\left(\mathrm{t}, 2 \mathrm{H}, \mathrm{OCH}_{2}\right), 3.81(\mathrm{~s}, 2 \mathrm{H}$, $\left.\mathrm{CH}_{2}\right), 2.1$ (s, $\left.3 \mathrm{H}, \mathrm{CH}_{3}\right) .{ }^{13} \mathrm{C}$ NMR $\left(75 \mathrm{MHz}, \mathrm{CDCl}_{3}\right): \mathrm{d}$ $170.5,144.2,138.2,134.2,130.7,128.6,125.6,122.0,119.5$, $116.5,85.4,72.6,65.8,63.4,52.0,32.3,17.5: \mathrm{MS}: \mathrm{m} / \mathrm{z}$ $\left(\mathrm{M}^{+}+\mathrm{H}\right)$ 483. Anal. Calcd for $\mathrm{C}_{24} \mathrm{H}_{23} \mathrm{ClN}_{4} \mathrm{O}_{3} \mathrm{~S}: \mathrm{C}, 59.68 ; \mathrm{H}$, 4.80 ; N, 11.60. Found: C, 59.48; H, 4.55; N, 11.49.

(R)-2-((2S,3S)-3-((1-(4-Chlorophenyl)-1H-1,2,3-triazol-4-yl)methoxy)-3,6-dihydro-2H-pyran-2-yl)-3-para-tolylthiazolidin-4-one (9e). M. p. $195-198{ }^{\circ} \mathrm{C}$. IR $(\mathrm{KBr})$ v 3126, 3014, 1746, 1632, 1625, 1442, 1434, 1341, 1331, 1228, $740 \mathrm{~cm}^{-1} .{ }^{1} \mathrm{H}$ NMR $\left(300 \mathrm{MHz}, \mathrm{CDCl}_{3}\right): \delta 8.05$ (s, $1 \mathrm{H}, \operatorname{Ar}-\mathrm{H}), 7.51(\mathrm{~d}, J=9.2 \mathrm{~Hz}, 2 \mathrm{H}, \mathrm{Ar}-\mathrm{H}), 7.45$ (d, $J=$ $8.7 \mathrm{~Hz}, 2 \mathrm{H}, \mathrm{Ar}-\mathrm{H}), 7.25$ (d, J = 8.2 Hz, 2H, Ar-H), 6.84 (d, $J=9.4 \mathrm{~Hz}, 2 \mathrm{H}, \mathrm{Ar}-\mathrm{H}), 5.72-5.68(\mathrm{~m}, 2 \mathrm{H},=\mathrm{CH}), 4.95(\mathrm{~s}$, $1 \mathrm{H}, \mathrm{CHS}), 4.59\left(\mathrm{~s}, 2 \mathrm{H}, \mathrm{OCH}_{2}\right), 4.04-3.99(\mathrm{~m}, 2 \mathrm{H}, \mathrm{CH})$, $3.98\left(\mathrm{t}, 2 \mathrm{H}, \mathrm{OCH}_{2}\right), 3.90\left(\mathrm{~s}, 2 \mathrm{H}, \mathrm{CH}_{2}\right), 2.32\left(\mathrm{~s}, 3 \mathrm{H}, \mathrm{CH}_{3}\right)$. ${ }^{13} \mathrm{C}$ NMR (75 MHz, $\left.\mathrm{CDCl}_{3}\right)$ : d 170.5, 144.2, 138.6, 136.2, $134.1,133.2,129.4,127.5,122.5,119.5,85.4,72.0,66.4$,
63.5, 51.5, 34.0, 21.4. MS: $m / z\left(\mathrm{M}^{+}+\mathrm{H}\right)$ 483. Anal. Calcd for $\mathrm{C}_{24} \mathrm{H}_{23} \mathrm{ClN}_{4} \mathrm{O}_{3} \mathrm{~S}$ : C, 59.68; $\mathrm{H}, 4.80 ; \mathrm{N}, 11.60$. Found: C, $59.58 ; \mathrm{H}, 4.65 ; \mathrm{N}, 11.43$.

(R)-2-((2S,3S)-3-((1-(4-Chlorophenyl)-1H-1,2,3-triazol-4-yl)methoxy)-3,6-dihydro-2H-pyran-2-yl)-3-(3hydroxyphenyl)thiazolidin-4-one (9f). M. p. 218-219 ${ }^{\circ} \mathrm{C}$. IR (KBr) v 3116, 3024, 1746, 1622, 1615, 1424, 1346, 1336, 1228, 1201, $749 \mathrm{~cm}^{-1}$. ${ }^{1} \mathrm{H}$ NMR $\left(300 \mathrm{MHz}, \mathrm{CDCl}_{3}\right)$ : $\delta 9.40$ (brs, $1 \mathrm{H}, \mathrm{Ph}-\mathrm{OH}$ ), 8.08 (s, $1 \mathrm{H}, \mathrm{Ar}-\mathrm{H}), 7.58$ (d, $J=9.3$ $\mathrm{Hz}, 2 \mathrm{H}, \mathrm{Ar}-\mathrm{H}), 7.49$ (d, $J=8.6 \mathrm{~Hz}, 2 \mathrm{H}, \mathrm{Ar}-\mathrm{H}), 6.83-6.76$ $(\mathrm{m}, 4 \mathrm{H}, \mathrm{Ar}-\mathrm{H}), 5.72-5.68(\mathrm{~m}, 2 \mathrm{H},=\mathrm{CH}), 4.94(\mathrm{~d}, J=5.2$ $\mathrm{Hz}, 1 \mathrm{H}, \mathrm{CHS}), 4.64\left(\mathrm{~s}, 2 \mathrm{H}, \mathrm{OCH}_{2}\right), 4.12\left(\mathrm{t}, 2 \mathrm{H}, \mathrm{OCH}_{2}\right)$, 4.01-3.94 (m, 2H, CH), $3.92\left(\mathrm{~s}, 2 \mathrm{H}, \mathrm{CH}_{2}\right) .{ }^{13} \mathrm{C}$ NMR $(75$ $\left.\mathrm{MHz}, \mathrm{CDCl}_{3}\right)$ : d 170.5, 158.2, 143.8, 134.5, 130.4, 128.6, $125.6,122.4,119.5,114.8,106.5,85.4,72.5,66.4,63.4,51.5$, 34.1. MS: $m / z\left(\mathrm{M}^{+}+\mathrm{Na}\right)$ 507. Anal. Calcd for $\mathrm{C}_{23} \mathrm{H}_{21} \mathrm{Cl}-$ $\mathrm{N}_{4} \mathrm{O}_{4} \mathrm{~S}: \mathrm{C}, 59.96 ; \mathrm{H}, 4.36 ; \mathrm{N}, 11.55$. Found: C, 59.28; H, $4.65 ; \mathrm{N}, 11.43$.

(R)-2-((2S,3S)-3-((1-(4-Chlorophenyl)-1H-1,2,3-triazol-4-yl)methoxy)-3,6-dihydro-2H-pyran-2-yl)-3-(4hydroxyphenyl)thiazolidin-4-one (9g). M. p. 273-275 ${ }^{\circ} \mathrm{C}$. IR (KBr) v 3119, 3028, 1741, 1619, 1611, 1420, 1336, 1326, 1218, 1213, $769 \mathrm{~cm}^{-1}$. ${ }^{1} \mathrm{H}$ NMR $\left(300 \mathrm{MHz}, \mathrm{CDCl}_{3}\right)$ : $\delta 9.42$ (brs, 1H, Ph-OH), 8.05 (s, 1H, Ar-H), 7.56 (d, $J=9.2$ $\mathrm{Hz}, 2 \mathrm{H}, \mathrm{Ar}-\mathrm{H}), 7.46$ (d, $J=8.4 \mathrm{~Hz}, 2 \mathrm{H}, \mathrm{Ar}-\mathrm{H}), 7.32(\mathrm{~d}, J=$ $8.6 \mathrm{~Hz}, 2 \mathrm{H}, \mathrm{Ar}-\mathrm{H}), 7.02(\mathrm{~d}, J=8.8 \mathrm{~Hz}, 2 \mathrm{H}, \mathrm{Ar}-\mathrm{H}), 5.89$ $5.80(\mathrm{~m}, 2 \mathrm{H},=\mathrm{CH}), 4.96(\mathrm{~d}, J=5.4 \mathrm{~Hz}, 1 \mathrm{H}, \mathrm{CHS}), 4.66(\mathrm{~s}$, $\left.2 \mathrm{H}, \mathrm{OCH}_{2}\right), 4.09\left(\mathrm{~d}, J=2 \mathrm{H}, \mathrm{OCH}_{2}\right), 4.04-3.98(\mathrm{~m}, 2 \mathrm{H}$, $\mathrm{CH}), 3.94\left(\mathrm{~s}, 2 \mathrm{H}, \mathrm{CH}_{2}\right) .{ }^{13} \mathrm{C}$ NMR $\left(75 \mathrm{MHz}, \mathrm{CDCl}_{3}\right): \mathrm{d}$ $170.9,154.1,144.4,134.9,134.8,128.8,127.2,125.6,123.2$, 119.4, 116.4, 85.4, 72.6, 66.5, 64.0, 51.6, 34.5. MS: $\mathrm{m} / z$ $\left(\mathrm{M}^{+}+\mathrm{H}\right)$ 485. Anal. Calcd for $\mathrm{C}_{23} \mathrm{H}_{21} \mathrm{ClN}_{4} \mathrm{O}_{4} \mathrm{~S}: \mathrm{C}, 59.96 ; \mathrm{H}$, 4.36; N, 11.55. Found: C, 59.38; H, 4.75; N,11.33.

General procedure for the synthesis of $10 a-g$. To a solution of alcohol $7(0.120 \mathrm{~g}, 0.465 \mathrm{mmol})$ in $\mathrm{CH}_{2} \mathrm{Cl}_{2}(5 \mathrm{~mL})$, a catalytic amount of IBX was added at $0{ }^{\circ} \mathrm{C}$ and stirred at room temperature for $30 \mathrm{~min}$. The reaction mixture was filtered and washed with $\mathrm{CH}_{2} \mathrm{Cl}_{2}(2 \times 10 \mathrm{~mL})$. It was dried $\left(\mathrm{Na}_{2} \mathrm{SO}_{4}\right)$ and evaporated to give aldehyde $7(0.110 \mathrm{~g})$ in quantitative yield as a yellow liquid, which was used as such for the next reaction.

To a stirred mixture of $7(0.110 \mathrm{~g}, 0.373 \mathrm{mmol})$, aromatic amine $(0.373 \mathrm{mmol})$ and anhydrous thiomalic acid $(0.140 \mathrm{~g}, 0.211 \mathrm{mmol})$ in dry toluene $(5 \mathrm{~mL}), \mathrm{ZnCl}_{2}$ $(0.100 \mathrm{~g}, 0.751 \mathrm{mmol})$ was added after $2 \mathrm{~min}$ and irradiated in microwave bath reactor at $280 \mathrm{~W}$ for $4-7$ minutes at $110^{\circ} \mathrm{C}$. After cooling, the filtrate was concentrated to dryness under reduced pressure and the residue was taken up in ethyl acetate. The ethyl acetate layer was washed with $5 \%$ sodium bicarbonate solution and finally with brine. The organic layer was dried over $\mathrm{Na}_{2} \mathrm{SO}_{4}$ and evaporated to dryness at reduced pressure. The crude product thus obtained was purified by column chromatography on silica 
gel (60-120 mesh) with hexane-ethyl acetate as the eluent. Under conventional method the reaction mixture in toluene $(10 \mathrm{~mL})$ was refluxed at $110{ }^{\circ} \mathrm{C}$ for the appropriate time (Table 1).

2-((2R)-2-((2S,3S)-3-((1-(4-Chlorophenyl)-1H-1,2,3triazol-4-yl)methoxy)-3,6-dihydro-2H-pyran-2-yl)-4oxo-3-phenylthiazolidin-5-yl)acetic acid (10a). M. p. $221-223^{\circ} \mathrm{C}$. IR (KBr) v 3114, 3004, 1740, 1724, 1610, 1600, 1430, 1330, 1320, 1219, $755 \mathrm{~cm}^{-1} .{ }^{1} \mathrm{H}$ NMR $(300 \mathrm{MHz}$, $\left.\mathrm{CDCl}_{3}\right): \delta 11.50\left(\mathrm{~s}, 1 \mathrm{H}, \mathrm{CO}_{2} \mathrm{H}\right), 8.09(\mathrm{~s}, 1 \mathrm{H}, \mathrm{ArH}), 7.58(\mathrm{~d}$, $J=9.2 \mathrm{~Hz}, 2 \mathrm{H}, \mathrm{ArH}), 7.49(\mathrm{~d}, J=8.9 \mathrm{~Hz}, 2 \mathrm{H}, \mathrm{Ar}-\mathrm{H}), 7.41-$ $6.76(\mathrm{~m}, 5 \mathrm{H}, \mathrm{Ar}-\mathrm{H}), 6.10$ (s, 1H, CHS), 5.84-5.79 (m, 2H, $=\mathrm{CH}), 4.65(\mathrm{t}, 1 \mathrm{H}, \mathrm{CH}), 4.52\left(\mathrm{~s}, 2 \mathrm{H}, \mathrm{OCH}_{2}\right), 4.10-4.08(\mathrm{~m}$, $2 \mathrm{H}, \mathrm{OCH}), 3.98\left(\mathrm{~d}, J=6.2 \mathrm{~Hz}, 2 \mathrm{H}, \mathrm{OCH}_{2}\right), 2.36(\mathrm{~d}, 2 \mathrm{H}$, $\left.\mathrm{CH}_{2}\right) .{ }^{13} \mathrm{C}$ NMR $\left(75 \mathrm{MHz}, \mathrm{CDCl}_{3}\right)$ : d 175.2, 173.0, 144.4, $141.5,134.5,128.5,125.6,122.4,119.4,86.4,72.5,66.4$, 49.5, 46.4, 38.6. MS: $m / z\left(\mathrm{M}^{+}+\mathrm{H}\right)$ 527. Anal. Calcd for $\mathrm{C}_{25} \mathrm{H}_{23} \mathrm{ClN}_{4} \mathrm{O}_{4} \mathrm{~S}: \mathrm{C}, 56.98 ; \mathrm{H}, 4.40 ; \mathrm{N}, 10.65$. Found: C, 56.78; H, 4.25; N,10.43.

2-((2R)-3-(4-Chlorophenyl)-2-((2S,3S)-3-((1-(4-chlorophenyl)-1H-1,2,3-triazol-4-yl)methoxy)-3,6-dihydro2H-pyran-2-yl)-4-oxothiazolidin-5-yl)acetic acid (10b). M. p. $269-271^{\circ} \mathrm{C}$. IR (KBr) v 3106, 3021, 1752, 1729, 1606, 1619, 1440, 1330, 1310, 1212, $741 \mathrm{~cm}^{-1} .{ }^{1} \mathrm{H}$ NMR $(300$ $\mathrm{MHz}, \mathrm{CDCl}_{3}$ ): $\delta 11.62\left(\mathrm{~s}, 1 \mathrm{H}, \mathrm{CO}_{2} \mathrm{H}\right), 8.12(\mathrm{~s}, 1 \mathrm{H}, \mathrm{Ar}-\mathrm{H})$, 7.54-7.49 (m, 6H, Ar-H), 7.30 (d, J = 8.3 Hz, 2H, Ar-H), $6.13(\mathrm{~s}, 1 \mathrm{H}, \mathrm{CHS}), 5.5-5.48(\mathrm{~m}, 2 \mathrm{H},=\mathrm{CH}), 4.59(\mathrm{t}, 1 \mathrm{H}$, $\mathrm{CH}), 4.5\left(\mathrm{~s}, 2 \mathrm{H}, \mathrm{OCH}_{2}\right), 4.09-4.05(\mathrm{~m}, 2 \mathrm{H}, \mathrm{OCH}), 3.96(\mathrm{~d}$, $\left.J=6.5 \mathrm{~Hz}, 2 \mathrm{H}, \mathrm{OCH}_{2}\right), 2.34\left(\mathrm{~d}, 2 \mathrm{H}, \mathrm{CH}_{2}\right) .{ }^{13} \mathrm{C} \mathrm{NMR}(75$ $\left.\mathrm{MHz}, \mathrm{CDCl}_{3}\right)$ : d 175.2, 173.2, 144.1, 139.6, 134.5, 134.1, 129.0, 127.4, 125.8, 122.4, 119.5, 86.5, 73.0, 66.8, 63.5, 49.3, 46.5, 39.1. MS: $m / z\left(\mathrm{M}^{+}+\mathrm{H}\right)$ 561. Anal. Calcd for $\mathrm{C}_{25} \mathrm{H}-$ ${ }_{22} \mathrm{Cl}_{2} \mathrm{~N}_{4} \mathrm{O}_{5} \mathrm{~S}$ : C, 53.48; H, 3.95; N, 9.98. Found: C, 53.18; $\mathrm{H}$, $3.65 ; \mathrm{N}, 9.78$.

2-((2R)-2-((2S,3S)-3-((1-(4-Chlorophenyl)-1H-1,2,3triazol-4-yl)methoxy)-3,6-dihydro-2H-pyran-2-yl)-3(4-nitrophenyl)-4-oxothiazolidin-5-yl)acetic acid (10c). M. p. $257-259^{\circ} \mathrm{C}$. IR (KBr) v 3104, 3026, 1736, 1728, 1616, $1601,1550,1425,1324,1314,1208,769 \mathrm{~cm}^{-1} .{ }^{1} \mathrm{H}$ NMR $\left(300 \mathrm{MHz}, \mathrm{CDCl}_{3}\right): \delta 11.42\left(\mathrm{~s}, 1 \mathrm{H}, \mathrm{CO}_{2} \mathrm{H}\right), 8.20(\mathrm{~d}, J=8.4$ $\mathrm{Hz}, 2 \mathrm{H}, \mathrm{Ar}-\mathrm{H}), 8.02$ (s, 1H, ArH), 7.48 (d, J=9.2 Hz, 2H, Ar-H), 7.42 (d, $J=8.6 \mathrm{~Hz}, 2 \mathrm{H}, \mathrm{Ar}-\mathrm{H}), 6.75$ (d, $J=9.6 \mathrm{~Hz}$, $2 \mathrm{H}, \mathrm{Ar}-\mathrm{H}), 6.15$ (s, 1H, CHS), 5.56-5.49 (m, 2H, =CH), $4.62\left(\mathrm{~s}, 2 \mathrm{H}, \mathrm{OCH}_{2}\right), 4.56(\mathrm{t}, 1 \mathrm{H}, \mathrm{CH}), 2.30\left(\mathrm{~d}, 2 \mathrm{H}, \mathrm{CH}_{2}\right)$. ${ }^{13} \mathrm{C} \mathrm{NMR}\left(75 \mathrm{MHz}, \mathrm{CDCl}_{3}\right)$ : d 175.2, 173.2, 143.6, 135.2, $134.2,131.5,128.9,127.4,125.6,124.1,122.5,119.4,86.1$, 72.8, 66.5, 63.9, 49.3, 46.5, 39.0. MS: $m / z\left(\mathrm{M}^{+}+\mathrm{H}\right) 573$. Anal. Calcd for $\mathrm{C}_{25} \mathrm{H}_{22} \mathrm{ClN}_{5} \mathrm{O}_{7} \mathrm{~S}: \mathrm{C}, 52.50 ; \mathrm{H}, 3.88 ; \mathrm{N}$, 12.24. Found: C, 52.38; H, 3.65; N, 12.01 .

2-((2R)-2-((2S,3S)-3-((1-(4-Chlorophenyl)-1H-1,2,3triazol-4-yl)methoxy)-3,6-dihydro-2H-pyran-2-yl)-4oxo-3-ortho-tolylthiazolidin-5-yl)acetic acid (10d). M. p. $243-245{ }^{\circ} \mathrm{C} . \mathrm{IR}(\mathrm{KBr}) \vee 3111,3014,1731,1719,1626$, $1625,1458,1449,1368,1331,1238,729 \mathrm{~cm}^{-1} .{ }^{1} \mathrm{H}$ NMR $\left(300 \mathrm{MHz}, \mathrm{CDCl}_{3}\right): \delta 11.60\left(\mathrm{~s}, 1 \mathrm{H}, \mathrm{CO}_{2} \mathrm{H}\right), 8.09(\mathrm{~s}, 1 \mathrm{H}$, Ar-H), 7.50 (d, J = 9.4 Hz, 2H, Ar-H), 7.45 (d, $J=8.5 \mathrm{~Hz}$, $2 \mathrm{H}, \mathrm{Ar}-\mathrm{H}), 6.86-7.10$ (m, 4H, Ar-H), 6.20 (s, 1H, CHS), 5.51-5.46 (m, 2H, =CH), $4.65\left(\mathrm{~s}, 2 \mathrm{H}, \mathrm{OCH}_{2}\right), 4.45(\mathrm{t}, 1 \mathrm{H}$, $\mathrm{CH}), 4.10-4.05(\mathrm{~m}, 2 \mathrm{H}, \mathrm{OCH}), 3.95(\mathrm{~d}, J=6.5 \mathrm{~Hz}, 2 \mathrm{H}$, $\left.\mathrm{OCH}_{2}\right), 2.35$ (d, 2H, CH $\left.\mathrm{MHz}, \mathrm{CDCl}_{3}\right): \mathrm{d} 175.4,173.5,144.5,138.6,135.0,134.5$, $130.5,129.5,126.0,122.0,119.4,116.5,86.5,73.0,67.0$, 64.0, 49.6, 46.5, 38.5, 17.5; MS: $m / z\left(\mathrm{M}^{+}+\mathrm{Na}\right)$ 563. Anal. Calcd for $\mathrm{C}_{26} \mathrm{H}_{25} \mathrm{ClN}_{4} \mathrm{O}_{5} \mathrm{~S}$ : C, 57.72; H, 4.66; N, 10.36 . Found: C, 57.58; H, 4.55; N,10.21.

2-((2R)-2-((2S,3S)-3-((1-(4-Chlorophenyl)-1H-1,2,3triazol-4-yl)methoxy)-3,6-dihydro-2H-pyran-2-yl)-4oxo-3-para-tolylthiazolidin-5-yl)acetic acid (10e). M. p. 207-209 ${ }^{\circ} \mathrm{C}$. IR (KBr) v 3136, 3024, 1756, 1729, 1612, 1605, 1432, 1424, 1331, 1321, 1248, $757 \mathrm{~cm}^{-1} .{ }^{1} \mathrm{H}$ NMR (300 $\left.\mathrm{MHz}, \mathrm{CDCl}_{3}\right): \delta 11.42\left(\mathrm{~s}, 1 \mathrm{H}, \mathrm{CO}_{2} \mathrm{H}\right), 8.06(\mathrm{~s}, 1 \mathrm{H}, \mathrm{Ar}-\mathrm{H})$, $7.55(\mathrm{~d}, J=9.5 \mathrm{~Hz}, 2 \mathrm{H}, \mathrm{Ar}-\mathrm{H}), 7.46(\mathrm{~d}, J=8.5 \mathrm{~Hz}, 2 \mathrm{H}$, Ar-H), 7.30 (d, $J=9.2 \mathrm{~Hz}, 2 \mathrm{H}, \operatorname{Ar}-\mathrm{H}), 6.84(\mathrm{~d}, J=9.6 \mathrm{~Hz}$, $2 \mathrm{H}, \mathrm{Ar}-\mathrm{H}), 6.15$ (s, 1H, CHS), 4.63 (s, 2H, $\left.\mathrm{OCH}_{2}\right), 4.45$ (t, $1 \mathrm{H}, \mathrm{CH}), 4.14-4.09(\mathrm{~m}, 2 \mathrm{H}, \mathrm{OCH}), 3.93(\mathrm{~d}, J=6.9 \mathrm{~Hz}, 2 \mathrm{H}$, $\left.\mathrm{OCH}_{2}\right), 2.30\left(\mathrm{~d}, 2 \mathrm{H}, \mathrm{CH}_{2}\right), 2.24\left(\mathrm{~s}, 3 \mathrm{H}, \mathrm{CH}_{3}\right) .{ }^{13} \mathrm{C} \mathrm{NMR}(75$ $\left.\mathrm{MHz}, \mathrm{CDCl}_{3}\right): \mathrm{d} 175.2,173.8,144.5,138.5,136.5,134.0$, $133.5,129.4,127.4,125.6,122.0,119.4,86.5,73.0,66.5$, 64.0, 49.5, 46.1, 39.0, 21.5; MS: $m / z\left(\mathrm{M}^{+}+\mathrm{H}\right)$ 541. Anal. Calcd for $\mathrm{C}_{26} \mathrm{H}_{25} \mathrm{ClN}_{4} \mathrm{O}_{5} \mathrm{~S}$ : C, 57.72; H, 4.66; N, 10.36 . Found: C, 57.52; H, 4.65; N,10.19.

2-((2R)-2-((2S,3S)-3-((1-(4-Chlorophenyl)-1H-1,2,3triazol-4-yl)methoxy)-3,6-dihydro-2H-pyran-2-yl)-3(3-hydroxyphenyl)-4-oxothiazolidin-5-yl)acetic acid (10f): M. p. $217-219{ }^{\circ} \mathrm{C}$. IR (KBr) v 3126, 3014, 1748, 1730, 1720, 1612, 1605, 1414, 1336, 1316, 1218, 1211, 779 $\mathrm{cm}^{-1} .{ }^{1} \mathrm{H}$ NMR $\left(300 \mathrm{MHz}, \mathrm{CDCl}_{3}\right): \delta 11.42(\mathrm{~s}, 1 \mathrm{H}, \mathrm{OH})$, 8.03 (s, 1H, Ar-H), 7.56 (d, J = 9.4 Hz, 2H, Ar-H), 7.48 (d, $J=8.3 \mathrm{~Hz}, 2 \mathrm{H}$, Ar-H), 7.14-6.95 (m, 4H, Ar-H), $6.16(\mathrm{~s}$, $1 \mathrm{H}, \mathrm{CHS}), 5.40(\mathrm{~s}, 1 \mathrm{H}, \mathrm{OH}), 4.65\left(\mathrm{~s}, 1 \mathrm{H}, \mathrm{OCH}_{2}\right), 4.10-4.03$ $(\mathrm{m}, 2 \mathrm{H}, \mathrm{OCH}), 3.98(\mathrm{t}, 1 \mathrm{H}, \mathrm{CH}), 2.35\left(\mathrm{~d}, 2 \mathrm{H}, \mathrm{CH}_{2}\right) .{ }^{13} \mathrm{C}$ $\mathrm{NMR}\left(75 \mathrm{MHz}, \mathrm{CDCl}_{3}\right)$ : d 175.3, 173.2, 158.3, 144.5, 134.9, $130.5,128.5,127.5,125.6,122.0,119.5,114.6,106.3,86.5$, 72.8, 66.5, 64.0, 49.5, 46.5, 39.0; MS: $m / z\left(\mathrm{M}^{+}+\mathrm{H}\right) 543$. Anal. Calcd for $\mathrm{C}_{25} \mathrm{H}_{23} \mathrm{ClN}_{4} \mathrm{O}_{6} \mathrm{~S}$ : C, 55.30; H, 4.26; N, 10.32. Found: C, 55.12; H, 4.05; N, 10.09 .

2-((2R)-2-((2S,3S)-3-((1-(4-Chlorophenyl)- $1 H-1,2,3-$ triazol-4-yl)methoxy)-3,6-dihydro-2H-pyran-2-yl)-3(4-hydroxyphenyl)-4-oxothiazolidin-5-yl)acetic acid (10g): M. p. $246-248{ }^{\circ} \mathrm{C}$. IR (KBr) v 3149, 3038, 1751, $1728,1629,1615,1440,1346,1316,1228,1203,739 \mathrm{~cm}^{-1}$. ${ }^{1} \mathrm{H} \mathrm{NMR}\left(300 \mathrm{MHz}, \mathrm{CDCl}_{3}\right.$ ): $\delta 11.39\left(\mathrm{~s}, 1 \mathrm{H}, \mathrm{CO}_{2} \mathrm{H}\right), 8.05$ (s, $1 \mathrm{H}, \mathrm{Ar}-\mathrm{H}), 7.58(\mathrm{~d}, J=9.5 \mathrm{~Hz}, 2 \mathrm{H}, \mathrm{Ar}-\mathrm{H}), 7.48(\mathrm{~d}, J=8.5$ $\mathrm{Hz}, 2 \mathrm{H}, \mathrm{Ar}-\mathrm{H}), 7.32$ (d, $J=8.8 \mathrm{~Hz}, 2 \mathrm{H}, \mathrm{Ar}-\mathrm{H}), 6.90$ (d, $J=$ $9.7 \mathrm{~Hz}, 2 \mathrm{H}, \mathrm{Ar}-\mathrm{H}), 6.08$ (s, 1H, CHS), 5.50-5.48 (m, 2H, 
$=\mathrm{CH}), 5.42(\mathrm{~s}, 1 \mathrm{H}, \mathrm{OH}), 4.60\left(\mathrm{~s}, 2 \mathrm{H}, \mathrm{OCH}_{2}\right), 4.15-4.10(\mathrm{~m}$, $2 \mathrm{H}, \mathrm{OCH}), 3.95\left(\mathrm{~d}, J=6.9 \mathrm{~Hz}, 2 \mathrm{H}, \mathrm{OCH}_{2}\right), 3.91(\mathrm{t}, 1 \mathrm{H}$, $\mathrm{CH}), 2.30$ (d, $2 \mathrm{H}, \mathrm{CH}_{2}$ ). ${ }^{13} \mathrm{C} \mathrm{NMR}\left(75 \mathrm{MHz}, \mathrm{CDCl}_{3}\right): \mathrm{d}$ $175.5,173.8,154.5,144.5,135.0,134.5,129.0,127.5,125.7$, 123.5, 119.5, 116.5, 86.5, 73.0, 67.0, 64.0, 49.5, 46.5, 39.0. MS: $m / z\left(\mathrm{M}^{+}+\mathrm{Na}\right) 565$. Anal. Calcd for $\mathrm{C}_{25} \mathrm{H}_{23} \mathrm{ClN}_{4} \mathrm{O}_{6} \mathrm{~S}: \mathrm{C}$, 55.30; H, 4.26; N, 10.32. Found: C, 55.09; H, 4.02; N, 10.19 .

\section{Conclusion}

A series of novel triazole linked thiazolidinone derivatives $9 \mathbf{a}-\mathbf{g}$ and $\mathbf{1 0 a}-\mathbf{g}$ was prepared and evaluated for their anticancer activity against four human cell lines and normal cell line (HEK 293). The screened compounds 9f and $10 \mathrm{f}$ exhibited potent anticancer activity compared to standard drug at the tested concentrations and $\mathbf{9 b}, \mathbf{1 0 b}, \mathbf{9 g}$ and $10 \mathrm{~g}$ exhibited potent anticancer activity compared to standard drug at the tested concentrations.

\section{Acknowledgements}

The authors are thankful to CSIR- New Delihi for the financial support (Project funding 02/247/15/EMR-II), Director, CSIR-IICT, Hyderabad, India, for NMR and MS spectral analysis.

\section{References}

1. (a) A. Farran, C. Cai, M. Sandoval, Chem. Rev. 2015, 115, 6811-6853. DOI:10.1021/cr500719h

(b) A. Varki, Glycobiology. 1993, 3, 97-130.

DOI:10.1093/glycob/3.2.97

2. N. Galonde, K. Nott, A. Debuigne, J. Chem. Tech. Biotechnol. 2012, 87, 451-471. DOI:10.1002/jctb.3745

3. (a) M. E.Caines, H. Zhu, M. Vuckovic, J. Bio. Chem. 2008, 283, 31279-31283. DOI:10.1074/jbc.C800150200

(b) H. Shirato, S. Ogawa, H. Ito, J. Virol. 2008, 82, 1075610767. DOI:10.1128/JVI.00802-08

(c) S. Nagaraj, K. Gupta, V. Pisarev, Nat. Med. 2007, 13, 828835. DOI:10.1038/nm1609

(d) K. E. Niederer, D. Morrow, J. L. Gettings, M. Irick, A. Krawiecki, J. L. Brewster, CellSignal. 2005, 17, 177-186.

DOI:10.1016/j.cellsig.2004.06.009

(e) H. Yagi, M. Yanagisawa, Y. Suzuki, J. Bio. Chem. 2010, 285, 37293-37301. DOI:10.1074/jbc.M110.157081

4. (a) C. R. Bertozzi, L. L. Kiessling, Chem. Glyc. Bio. Sci. 2001, 291, 2357-2364. DOI:10.1126/science.1059820

(b) T. Angata, A. Varki, Chem. Rev. 2002, 102, 439-469.

DOI:10.1021/cr000407m

(c) R. R. Schmidt, W. Kinzy, Adv. Carbohy. Chem. Biochem. 1994, 50, 21-123.

DOI:10.1016/S0065-2318(08)60150-X

(d) V. K. Tiwari, B. B. Mishra, Research Signpost, Trivandrum.
India. 2011, 41, 1-45

5. (a) V. K. Tiwari, R. C. Mishra, A. Sharma, R. P. Tripathi, Mini Rev. Med. Chem. 2012, 12, 1497-1519.

DOI:10.2174/138955712803832654

(b) V. K. Tiwari, B. B. Mishra, K. B. Mishra, N. Mishra, A. S. Singh, X. Chen, Chem. Rev. 2016, 116, 3086-3240.

DOI:10.1021/acs.chemrev.5b00408

(c) K. B. Mishra, B. B.Mishra, V. K. Tiwari, Carbohyd. Res. 2014, 399, 2-7. DOI:10.1016/j.carres.2014.09.001

(d) D. Kumar, K. B. Mishra, B. B. Mishra, V. K. Tiwari, Steroids, 2014, 80, 71-79.

DOI:10.1016/j.steroids.2013.11.022

6. R. Huisgen, G. Szeimies, L. Moebius, Chem. Ber. 1967, 100, 2494-2507. DOI:10.1002/cber.19671000806

7. (a) R. Huisgen, Angew. Chem. Int. Ed. 1963, 2, 565-598. DOI:10.1002/anie.196305651

(b) R. Huisgen, Angew. Chem. Int. Ed. 1963, 2, 633-696. DOI:10.1002/anie.196306961

(c) R. Huisgen, 1,3-Dipolar cycloadditions - introduction, survey, mechanism. In 1,3-Dipolar Cycloaddition Chemistry, Ed. A. Padwa. New York: Wiley. 1984, 1-176.

DOI:10.1002/chin.198518341

(d) V. V. Rostovtsev, L. G. Green, V. V. Fokin, K. B. Sharpless, Angew. Chem. Int. Ed. 2002, 412, 2596-2599.

DOI:10.1002/1521-3773(20020715)41:14<2596::AID-ANIE 2596>3.0.CO;2-4

8. (a) F. G. Heras, R. Alonso, G. Alonso, J. Med. Chem.1979, 22, 496-501. (b) J. C. Morris, J. Chiche, C. Grellier, J. Med. Chem. 2011, 54, 6905-6918. (c) S. B. Ferreira, A. C. R. Sodero, M. F. C. Cardoso, J. Med. Chem. 2010, 53, 2364-2375.

9. (a) K. D. Hani, D. A. Leigh, Chem. Soc. Rev. 2010, 39, 12401251. DOI:10.1039/B901974J

(b) C. O. Kappe, E. van der Eycken, Chem. Soc. Rev. 2010, 39, 1280-1290. DOI:10.1039/B901973C

(c) A. H. El-Sagheer, T. Brown, Chem. Soc. Rev. 2010, 39, 1388-1405. DOI:10.1039/b901971p

(d) A. Qin, J. W. Y. Lam, B. Z. Tang, Chem. Soc. Rev. 2010, 39, 2522-2544. DOI:10.1039/b909064a

(e) M. Meldal, C. W. Tornoe, Chem. Rev. 2008, 108, 29523015. DOI:10.1021/cr0783479

(f) H. Nandivada, X. Jiang, J. Lahann, Adv. Mater. 2007, 19, 2197-2208. DOI:10.1002/adma.200602739

(g) Y. L. Angell, K. Burgess, Chem. Soc. Rev. 2007, 36, 16741689. DOI:10.1039/b701444a

(h) D. Fournier, R. Hoogenboom, U. S. Schubert, Chem. Soc. Rev. 2007, 36, 1369-1380.

DOI:10.1039/b700809k

(i) J. E. Moses, A. D. Moorhouse, Chem. Soc. Rev. 2007, 36, 1249-1262. DOI:10.1039/B613014N

(j) J. F. Lutz, Angew. Chem. Int. Ed. 2007, 46, 1018-1025.

DOI:10.1002/anie.200604050

(k) A. Dondoni, Chem. Asian J. 2007, 2, 700-708.

DOI:10.1002/asia.200700015

(l) H. C. Kolb, K. B. Sharpless, Drug Dis. Today, 2003, 8, 1128-1137. DOI:10.1016/S1359-6446(03)02933-7

10. A. Brick, J. Muldoon, Y.-C. Lin, J. H. Elder, D. S. Goodsell, 
A. J Olson, V. V. Fokin, K. B. Sharpless, C.-H. Wong, ChemBioChem 2003, 4, 1246-12148. (b) M. J. Soltis, H. J. Yeh, K. A. Cole, N. Whittaker, R. P. Wersto, E. C. Kohn, Drug Metab. Dispos. 1996, 24, 799-806. DOI:10.1002/cbic.200300724

11. (a) W.-Q. Fan, A. R. Katritzky, 1, 2,3-Triazoles, In Comprehensive Heterocyclic Chemistry II. Ed. A. R. Katritzky, C. W. Rees, V. Scriven, Elsevier, Oxford, 1996, 4, 1-126, pp. 905-1006. DOI:10.1016/B978-008096518-5.00079-4

(b) M. Whiting, J. Muldoon, Y.-C. Lin, S. M. Silverman, W. Lindstrom, A. J. Olson, H. C. Kolb, M. G. Finn, K. B. Sharpless, J. H. Elder, V. V. Fokin, Angew. Chem. Int. Ed. 2006, 45, 1435-1439. DOI:10.1002/anie.200502161

(c) Y. Bourne, H. C. Kolb, Z. Radić, K. B. Sharpless, P. Taylor, P. Marchot, Proc. Natl. Acad. Sci. U. S. A. 2004, 101, 14491454. DOI:10.1073/pnas.0308206100

(d) W. G. Lewis, G. Green, F. Z. Grynszpan, Z. Radić, P. R. Carlier, P. Taylor, M. G. Finn, K. B. Sharpless, Angew. Chem. Int. Ed. 2002, 41, 1053-1057.

DOI:10.1002/1521-3773(20020315)41:6\%3C1053::AID-ANIE 1053\%3E3.0.CO;2-4

12. R. Huisgen, A. Padwa, 1,3-Dipolar Cycloaddition Chemistry, Wiley, New York, 1984, 1, 1-176.

13. (a) N. A. Al-Maoudi, A. Y. Al-Soud, Tetrahedron Lett. 2002, 43, 4021-4022. DOI:10.1016/S0040-4039(02)00733-5

(b) B. H. M. Kuijpers, S. Groothuys, A. B. R. Keereweer, P. J. L. M. Quaedflieg, R. H. Blaauw, F. L. van Delft, F. P. J. T. Rutjes, Org. Lett. 2004, 6, 3123-3126. DOI:10.1021/ol048841o

(c) C. Srinivas, X. Fang, Q. Wang, Tetrahedron Lett. 2005, 46, 2331-2334. DOI:10.1016/j.tetlet.2005.01.175

(d) S. Hotha, R. I. Anegundi, A. A. Natu, Tetrahedron Lett. 2005, 46, 4585-4588. DOI:10.1016/j.tetlet.2005.05.012

(e) S. Hotha, S. Kashyap, J. Org. Chem. 2006, 71, 364-367. DOI:10.1021/jo051731q

14. (a) R. B. Patel, P. S. Desai, K. R. Desai, K. H. Chikalia, Indian J. Chem., Sect. B 2006, 45B, 773-778.

(b) A. Bishnoi, S. Krishna, C. K. M. Tripathi, Indian J. Chem., Sect. B 2006, 45B, 2136-2139.

15. C. V. Dave, M. C. Shukla, Indian J. Chem., Sect. B 2000, 39B, 210-214.

16. W. J. Doran, H. A. Shoukla, J. Org. Chem. 1939, 93, 626-633.

17. J. S. Biradar, S. Y. Manjunath, Indian J. Chem., Sect. B 2004, 43B, 389-392.

18. (a) N. P. Buu-Hoi, N. D. Young, F. Binon, J. Chem. Soc. 1948, 70, 3436-3439. DOI:10.1021/ja01190a064

(b) A. Gangiee, G. Adaer, J. Med. Chem. 1999, 42, 2447-2455. DOI:10.1021/jm990079m

(c) T. Srivastava, K. G. Anil, H. Wahajul, S. Sudhir, B. K. Setu, Arkivoc 2005, (ii), 120-130.

19. B. R. Shah, N. C. Desai, P. B. Trivedi, Indian J. Heterocycl. Chem., Sect. B 1993, 2, 249-252.

20. L. L. Chijavasakaya, I. Gopnovich, R. S. Chelchenko, Chem Abstr. 1969, 70, 10641y.

21. (a) A. Chimmiri, S. Grasso, A. M. Monforte, P. Monoforte, M. Zappala, Il Farmaco 1991, 46, 817-823.

(b) A. Chimmiri, S. Grasso, A. M. Monforte, P. Monoforte, M. Zappala, Il Farmaco 1991, 46, 925-933. (c) A. Chimmiri, S. Grasso, C. Molica, A. M. Monforte, P . Monoforte, M. Zappala, Il Farmaco, 1996, 51, 279-282.

22. V. M. Barot, Asian J. Chem. 1996, 100, 8802-8806. DOI:10.1021/jp952984y

23. M. H. Khan, Nizamuddin, J. Food Agric. Chem. 1995, 43, 2719-2729.

24. V. K. Ahulwalia, C. Gupta, Heterocycles 1991, 32, 907-914.

25. (a) H. D. Trautmen, L. M. Longe, J. Am. Chem. Soc. 1948, 70, 3434-3436. DOI:10.1021/ja01190a063

(b) A. R. Surray, J. Am. Chem. Soc. 1949, 71, 3354-3356.

DOI:10.1021/ja01178a023

26. M. R. Manrao, J. Monika, V. K. Kaul, Pl. Dis. Res. 1997, 12, 94-96.

27. T. Saini, S. Kumar, B. Narsimhan, Cent. Nerv. Syst. Agents. Med. Chem. 2015, 16, 19-28.

DOI:10.2174/1871524915666150608103224

28. T. Kato, T. Ozaki, N. Ohi, Tetrahedron Assymmetry 1999, 10, 3963-3968. DOI:10.1016/S0957-4166(99)00441-3

29. (a) R. B. Desyk, B. S. Zimenskovsky, Current. Org. Chem. 1992, 35, 2712-2719.

(b) A. Usha, O. Swathi, B. Dinesh, L. T. Ganpat, Arkivoc 2006, (xiii), 83-89. DOI:10.3998/ark.5550190.0007.709

30. Y. Tanabe, H. Yamamoto, M. Murakami, I. K.Yanag, Y. Kubota, Y. Sanimistu, G. Suzukamo, J. Chem. Soc, Perkin Trans. 1 1975, 7, 935-938.

31. (a) C. O. Kappe, Angew. Chem. Int. Ed. 2004, 43, 6250-6284. DOI:10.1002/anie.200400655

(b) C. O. Kappe, D. Dallinger, Nat. Rev. Drug Discovery 2006, 5, 51-63. DOI:10.1038/nrd1926

32. Y. Kumar, V. Bahadur, A. K. Singh, V. S. Parmer, E. V. van der Eycken, B. K. Singh, Beilstein J. Org. Chem. 2014, 10, 113-118.

33. V. Sharma, P. K. Jaiswal, D. K. Yadav, M. Saran, J. Prikhodko, M. Mathur, A. K. Swami, I. V. Mashevskaya, S. Chaudhary, Acta Chim. Slov. 2017, 64, 988-1004.

DOI:10.17344/acsi.2017.3709

34. B. Prek, B.Stanovnik, Acta Chim. Slov. 2017, 64, 798-803.

35. B. L. Turek, M. Kočevar, K. Kranjc, F. Perdih, Acta Chim. Slov. 2017, 64, 737-746.

36. L. Moradi, M. A. Sadegh, Acta Chim. Slov. 2017, 64, 506-512. DOI:10.17344/acsi.2017.3417

37. A. Srinivas, M. Sunitha, P. Karthik, G. Nikitha, K. Raju, B. Ravinder, S. Anusha,T. Rajasri, D. Swapna, D. Swaroopa, K. Srinivas, K. Vasumathi Reddy, J. Heterocycl. Chem. 2017, 54, 3250-3257. DOI:10.1002/jhet.2943

38. A. Srinivas, M. Sunitha, P. Karthik, K. V. Reddy, Acta Chim. Slov. 2017, 64, 1030-1041.

DOI:10.17344/acsi.2017.3805

39. A. Srinivas, M. Sunitha, K. Raju, B. Ravinder, S. Anusha, T. Rajasri, P. Swapna, D. Sushmitha, D. Swaroopa, G. Nikitha, C. G. Rao, Acta Chim. Slov. 2017, 64, 319-331.

DOI:10.17344/acsi.2016.3153

40. A. Srinivas, Acta Chim. Slov. 2016, 63, 173-179.

41. A. Srinivas, M. Sunitha, Indian J. Chemistry, Sect. B 2016, 55B, 102-109.

42. A. Srinivas, M. Sunitha, Indian J. Chemistry, Sect. B 2016, 55B, 231-239. 
43. C. S. Reddy, A. Srinivas, M. Sunitha, A. Nagaraj, J. Heterocycl. Chem. 2010, 47, 1303-1309. DOI:10.1002/jhet.474

44. A. Srinivas, C. S. Reddy, A. Nagaraj, Chem. Pharm. Bull. 2009, 57, 685-693.

45. C. S. Reddy, A. Srinivas, A. Nagaraj, J. Heterocycl. Chem. 2009, 46, 497-502. DOI:10.1002/jhet.100
46. C. S. Reddy, A. Srinivas, A. Nagaraj, J. Heterocycl. Chem. 2008, 45, 1121-1125. DOI:10.1002/jhet.5570450428

47. T. Mossamen, J. Immunol. Methods 1983, 65, 55-63. DOI:10.1016/0022-1759(83)90303-4

\section{Povzetek}

S kondenzacijo (2S,3S)-3-((1-(4-klorofenil)-1H-1,2,3-triazol-4-il)metoksi)-3,6-dihidro-2H-piran-2-karbaldehida $\mathrm{Z}$ merkapto kislinami in primarnimi amini v prisotnosti $\mathrm{ZnCl}_{2}$ smo pod pogoji obsevanja $\mathrm{z}$ mikrovalovi in klasičnim segrevanjem pripravili seriji $(R)-2-((2 S, 3 S)-3-((1-(4-k l o r o f e n i l)-1 H-1,2,3$-triazol-4-il)metoksi)-3,6-dihidro-2H-piran2-il)-3-feniltiazolidin-4-onov 9a-g in 2-((2R)-2-((2S,3S)-3-((1-(4-klorofenil)-1H-1,2,3-triazol-4-il)metoksi)-3,6-dihidro-2H-piran-2-il)-4-okso-3-feniltiazolidin-5-il)ocetnih kislin 10a-g. Nove spojine smo karakterizirali z IR, NMR, MS in elementno analizo. Raziskali smo citotoksičnost na seriji štirih različnih človeških tumorskih celičnih linij: A549 iz človeških alveolarnih adenokarcinomskih epitelijskih celic (ATCC No. CCL-185), Hela iz človeških rakastih celic materničnega vratu (ATCC No. CCL-2), MDA-MB-231 iz človeških adenokarcinomskih celic dojk (ATCC No. HTB22) in HEK 239 (normalne človeške embrionske celice ledvic) s pomočjo MTT analize. Izmed testiranih spojin sta 9e in 10e pokazali največjo učinkovitost proti MCF-7 celični liniji raka dojke z $\mathrm{IC}_{50}$ vrednostmi 1.91 in $1.95 \mu \mathrm{M}$, spojine $9 \mathbf{b}, \mathbf{1 0 b}$, $9 \mathrm{~g}$ in $\mathbf{1 0 g}$ pa so pokazale obetavno aktivnost proti MDA-MB-231 in Hela celicam $\mathrm{z} \mathrm{IC}_{50}$ vrednostmi 5.84, 5.74, 7.89 in $7.65 \mu \mathrm{M}$.

Except when otherwise noted, articles in this journal are published under the terms and conditions of the Creative Commons Attribution 4.0 International License 